Counsellia: Jurnal Bimbingan dan Konseling, 9 (1), 2019| 39 - 52

Copyright (C2019 Universitas PGRI Madiun

ISSN: 2088-3072 (Print) / 2477-5886 (Online)

Available online at: http://e-journal.unipma.ac.id/index.php/JBK

DOI: $10.25273 /$ counsellia.v9i1.3690

\title{
Efektivitas Logoterapi terhadap peningkatan harga diri remaja pecandu narkoba di Pondok Pesantren Bidayatussalikin Yogyakarta
}

\author{
Diani Naraasti ${ }^{1}$, Budi Astuti ${ }^{2}$ \\ ${ }^{1}$ Pascasarjana Bimbingan dan Konseling, Universitas Negeri Yogyakarta, \\ Yogyakarta \\ dianinaraasti@gmail.com \\ ${ }^{2}$ Pascasarjana Bimbingan dan Konseling, Universitas Negeri Yogyakarta, \\ Yogyakarta \\ budi_astuti@uny.ac.id
}

\begin{abstract}
Abstrak
Logoterapi melihat optimisme sebagai sumber kekuatan dan menanamkan pendekatan positif untuk mengatasi permasalahan hidup yang dialami. Sikap optimis dapat membantu remaja pecandu narkoba memiliki harapan untuk masa depan, dengan begitu remaja pecandu narkoba akan memiliki harga diri tinggi dalam menilai dirinya sendiri dan mampu untuk bersosialisasi di lingkungan. Tujuan dari penelitian ini adalah melihat keefektifan logoterapi terhadap peningkatan harga diri remaja pecandu narkoba di Pondok Pesantren Bidayatussalikin Yogyakarta. Metode penelitian yang digunakan adalah quasi ekperimen dengan menggunakan non equivalent control grup design, masing-masing kelompok eksperimen dan kontrol akan diberikan pretest dan posttest. Hasil yang diperoleh dalam penelitian ini adalah logoterapi efektif terhadap peningkatan harga diri remaja pecandu narkoba di Pondok Pesantren Bidayatussalikin.
\end{abstract}

Kata Kunci: Logoterapi, harga diri, remaja pecandu narkoba.

\begin{abstract}
Logotherapy sees optimism as a source of strength and instills a positive approach to overcome life's problems experienced. An optimistic attitude can help adolescent drug addicts have hope for the future, so adolescent drug addicts will have high self-esteem in assessing themselves and being able to socialize in the environment. The purpose of this study was to look at the effectiveness of logotherapy to increase the self-esteem of adolescent drug addicts in the Bidayatussalikin Islamic Boarding School in Yogyakarta. The research method used was quasi-experiment using non equivalent control group design, each experimental group and control group will be given a pretest and posttest. The results obtained in this study were effective logotherapy to increase the self-esteem of adolescent drug addicts in Bidayatussalikin Islamic Boarding School.
\end{abstract}

Keywords: Logotherapy, self-esteem, adolescent drug addicts. 



\section{PENDAHULUAN}

Berdasarkan data BNN (Koran Sindo, 15 November 2017) menyatakan jumlah penduduk Indonesia yang memakai narkoba sebanyak 5,1 juta jiwa dan merupakan jumlah terbesar di Asia, $40 \%$ dari jumlah tersebut adalah pemakai narkoba pada golongan pelajar dan mahasiswa. Kepala Bidang Pemberantasan Narkoba BNNP DIY AKBP Mujiyana menyatakan kepada Detik.com (16 Juli 2017) dari jumlah penduduk Yogyakarta sebesar 3,6 juta jiwa, sebanyak 2,6 persen adalah pengguna narkoba dan jumlah pengguna tersebut paling banyak diisi oleh pelajar dan mahasiswa. Hal tersebut membuat Yogyakarta menjadi provinsi yang berada pada tingkat pertama untuk jumlah terbanyak penyalahgunaan narkoba hingga saat ini.

Narkoba sangat dekat dengan kehidupan remaja karena remaja adalah lapisan masyarakat yang paling rentan karena pengalaman yang tidak memadai dan kurangnya informasi tentang keterampilan yang diperlukan untuk menolak ajakan oranglain untuk melakukan pelanggaran yang bersifat kriminal. Berdasarkan UU tentang Narkotika No 35 tahun 2009 pasal 1 no 13 pecandu narkoba adalah orang yang menggunakan atau menyalahgunakan narkoba dan dalam keadaan ketergantungan pada narkoba baik secara fisik maupun psikis dan harus menjalani proses rehabilitasi. Selama proses rehabilitasi para pecandu narkoba akan dijauhkan dari interaksi sosial dengan lingkungan, hal ini dimaksudkan agar pecandu narkoba dapat fokus menjalani pengobatan dan terhindar dari bujukan-bujukan yang mungkin dilakukan orang lain untuk kembali menggunakan narkoba.

Pondok

Pesantren

Bidayatussalikin Sleman Yogyakarta merupakan salah satu rehabilitasi narkoba yang banyak di huni oleh remaja pecandu narkoba. Kebanyakan remaja pecandu narkoba tersebut masih berada pada usia sekolah ketika menjalani proses rehabilitasi, hal tersebut membuat remaja pecandu mengalami putus sekolah. Berdasarkan hasil wawancara kepada Ketua Pengurus 
Ponpes Bidayatussalikin (20

Februari 2018) remaja putus sekolah karena narkoba banyak yang sudah tidak memiliki cita-cita dan harapan lagi untuk masa depannya, hal itu berpengaruh pada penerimaan diri remaja terhadap dirinya dan masalah tersebut membuat remaja memiliki harga diri rendah karena merasa tidak lagi memiliki harapan hidup. Faktor keluarga dan teman-teman yang secara tiba-tiba menjauh tidak pernah melakukan kunjungan di tempat rehabilitasi membuat remaja berkecil hati dan tidak memiliki semangat. Penilaian terhadap dirinya yang negatif membuat remaja merasa tidak berharga dan memunculkan kemungkinan relapse (kondisi pecandu menggunakan narkoba kembali setelah menyelesaikan rehabilitasi narkoba) lebih besar.

\section{Ponpes Bidayatussalikin} sebagai tempat rehabilitasi telah melakukan banyak upaya untuk mengatasi permasalahan harga diri rendah pada pecandu narkoba salah satunya dengan melakukan konseling individu. Akan tetapi, upaya tersebut belum mendapatkan hasil maksimal karena belum adanya tenaga ahli dari lulusan bimbingan dan konseling yang memberikan layanan di rehabilitasi narkoba tersebut.

Berdasarkan hasil wawancara yang dilakukan oleh peneliti kepada Rizka Amalia salah satu staff rehabilitasi BNNP Yogyakarta pada tanggal 14 Februari 2018, menyatakan proses rehabilitasi yang dilakukan banyak menimbulkan permasalahan baru pada pribadi pecandu sendiri seperti, perasaan terbuang tidak diinginkan, tertekan karena merasa terpenjara, harga diri rendah karena tidak memiliki harapan lagi akan masa depannya, takut ditolak oleh lingkungan, dan rasa bersalah yang sangat besar membuat pecandu sering mengalami stres. Permasalahan tersebut yang membuat banyak remaja mengalami kondisi relapse setelah proses rehabilitasi selesai dilakukan. BNNP Yogyakarta menganjurkan peneliti untuk melakukan penelitian di Pondok Pesantren Bidayatussalikin yang memiliki banyak pecandu remaja dengan permasalahan utamanya adalah harga diri rendah 
yang menjadi salah faktor selesai) pada pecandu narkoba. kemungkinan terjadinya relapse Adapun profil harga diri remaja di (kondisi kembali menggunakan Ponpes Bidayatussalikin dapat dilihat narkoba setelah proses rehabilitasi pada tabel di bawah ini:

Tabel 1. Gambaran Umum Harga Diri Remaja Pecandu Narkoba di Pondok Pesantren Bidayatussalikin Yogyakarta

\begin{tabular}{ccc}
\hline Kategori & Frekuensi & Presentase \\
\hline Tinggi & 2 & 14 \\
Sedang & 2 & 14 \\
Rendah & 10 & 72 \\
Jumlah & 14 & 100 \\
\hline
\end{tabular}

Sebanyak $72 \%$ remaja pecandu narkoba di Ponpes Bidayatussalikin Yogyakarta masih memiliki harga diri rendah. Hal tersebut ditandai dengan masih kesulitannya pecandu beradaptasi dengan lingkungan di rehabilitasi, masih sering terjadi pecandu yang kabur dari tempat rehabilitasi, pecandu melakukan penolakan terhadap kegiatan rehabilitasi yang dilakukan oleh pembina rehabilitasi.

Santrock menyatakan merokok dan alkohol dipandang oleh remaja sebagai lambang kedewasaan (Santrock, 2003). Berawal dari rokok dan alkohol inilah remaja mengenal kehidupan dewasa yang salah, remaja yang sudah merasakan ketagihan akan terus mencoba hal lainnya yang dapat membuat remaja lebih terlihat keren di antara teman lainnya, narkoba salah satunya. Menurut Papalia dan Olds (Jahja, 2011) masa remaja adalah masa transisi atau masa peralihan dari masa kanak-kanak menuju masa dewasa, yang umumnya dimulai pada usia antara 12 atau 13 tahun dan berakhir pada usia akhir belasan tahun atau awal dua puluh tahun. Masa transisi ini membuat remaja memiliki keingintahuan yang besar pada kehidupan orang dewasa disekitarnya. Menurut (Guindon, 2010) ada 4 motivasi yang dimiliki oleh remaja untuk menggunakan alkohol dan obat-obatan terlarang lainnya, yaitu membantu mempertahankan suasana hati yang 
senang, aktivitas sosial dengan teman lebih menyenangkan, sebagai bentuk penyesuaian diri dari lingkungan dan sebagai cara mengatasi atau mengurangi perasaan negatif seperti kecemasan, stres, harga diri rendah dan kurang percaya diri. berdasarkan penelitian yang dilakukan oleh Orth, Trzesniewki dan Robins menyatakan bahwa perempuan memiliki harga diri yang lebih rendah dari pada laki-laki (Orth, Trzesniewki dan Robins, 2010).

Menurut Plummer (2005) harga diri rendah sangat berkaitan erat dengan kehidupan remaja dengan penyalahgunaan alkohol dan narkoba, dan ini dapat memicu masalah lainnya seperti terjadi kehamilan di luar nikah (free sex) yang banyak dilakukan kalangan remaja saat ini. (Guindon, 2010) menyatakan harga diri rendah telah terbukti berkaitan dengan banyak fenomena negatif seperti tingkat kehamilan pada remaja semakin tinggi, penyalahgunaan alkohol dan narkoba semakin banyak dilakukan oleh kalangan remaja, kekerasan baik dengan teman sebaya atau kekerasan dalam sebuah hubungan, depresi atau stres, kecemasan sosial dan bunuh diri. Penelitian yang dilakukan (Zamboanga dan Schwartz, 2009) menyatakan ada hubungan antara harga diri dan stress yang dialami remaja di Michigan Amerika dengan penyalahgunaan narkoba dan alkohol.

Sullivan menyatakan bahwa harga diri adalah kebutuhan sosial dari masing-masing individu untuk diterima dan disukai oleh lingkungan, harga diri digunakan untuk menyesuaikan diri dengan harapan social (Guindon, 2010). Penting untuk para pecandu membangun harga diri yang tinggi, karena dengan harga diri tinggi pecandu memiliki harapan untuk menata masa depan sehingga dapat kembali ke masyarakat. Menurut (Murk, 2006) melibatkan kurangnya kompetensi dan kelayakan yang dimiliki manusia. Harga diri rendah banyak dikaitkan dengan hal-hal seperti hatihati, penakut, kurang memiliki inisiatif, selalu melakukan penghindaran, merasa tidak aman, kecemasan berlebihan dan stres atau depresi. Santrock (2013) harga diri 
tinggi mengacu pada pandangan diri yang sangat menguntungkan, seperti harga diri akan sangat berperan pada prestasi di sekolah dan hubungan individu dengan orang sekitar.

(Schab, 2013) penting bagi individu memiliki harga diri yang sehat, dengan begitu individu akan mampu menerima kelemahan dan menghargai kekuatan yang dimiliki. Berdasarkan penelitian yang dilakukan (Pradana, 2015) menyatakan adanya hubungan antara harga diri dengan ketergantungan narkoba pada remaja, yang artinya semakin tinggi harga diri remaja maka semakin rendah penyalahgunaan narkoba pada remaja tersebut dan sebaliknya semakin rendah harga diri remaja maka semakin tinggi tingkat penyalahgunaan narkoba. Untuk itu perlu invidu memahami aspek-aspek yang ada dalam harga diri, (Coopersmith, 1967) menyebutkan empat aspek yang terdapat dalam harga diri, yaitu:

a. Power (kekuasan atau kekuatan) merupakan kemampuan untuk mempengaruhi dan mengendalikan orang lain, b. Significance

(keberartian)

merupakan penerimaan,

perhatian, dan kasih sayang dari orang lain,

c. Virtue (kebajikan) merupakan ketaatan terhadap aturan-aturan moral dan etika, oleh karena itu kesuksesan dalam area virtue ditandai dengan ketaatan terhadap prinsip-prinsip moral, etika dan agama,

d. Competence (kompetensi) dimaksudkan sebagai keberhasilan dalam mencapai prestasi sesuai tuntutan, baik tujuan atau cita-cita, baik secara pribadi maupun yang berasal dari lingkungan sosial

Menurut (Kimble dan Ellor, 2000) secara ontologis, logoterapi mengatasi masalah-masalah kemanusian tingkat tinggi untuk memahami makna dan nilai-nilai, kebebasan dan tanggungjawab, hati nurani dan komitmen, keputusan dan tujuan hidup dibalik penderitaan seseorang. Makna kehidupan yang dimiliki setiap manusia membuat manusia tersebut menemukan arti kehidupan yang diinginkan, dengan memiliki makna hidup manusia 
mempunyai semangat dan harapan untuk hidup yang lebih baik di masa yang akan datang.

Menurut Frankl (Batthyany, 2016) logoterapi melihat optimisme sebagai sumber kekuatan dan menanamkan pendekatan positif untuk mengatasi permasalahan hidup yang dialami. Hal ini menanamkan bahwa disetiap kesulitan atau penderitaan sekalipun manusia tetap bisa mengambil sisi positif dan makna yang baik dari pengalaman tersebut dan bahwa masih ada harapan dalam sebuah kegagalan. Menurut (Frankl, 1992) terdapat 3 teknik dalam logoterapi yaitu paradoxical intention (intensi paradoksikal), de-reflection dan modification of attitudes (modifikasi sikap).

(Graber, 2004) dalam penelitiannya menyatakan bahwa logoterapi menerapkan kekuatan semangat manusia untuk mengatasi kesulitan yang terjadi setelah penderitaan manusia dalam masalah apapun. Logoterapi membuat manusia memiliki kemampuan untuk secara kreatif mengubah aspek negatif yang terjadi dalam hidup menjadi aspek yang positif. Logoterapi menuntun konseli untuk mencari alternatif pada suatu masalah agar konseli dapat menerima dan mampu menyelesaikan masalahnya. Melton dan (Schulenberg, 2008) menyatakan bahwa tujuan dari logoterapi adalah memberikan konstribusi untuk manusia dalam merespon berbagai masalah internal dan eksternal, membuat manusia memiliki motivasi utama yang memungkinkan manusia memiliki makna hidup yang diinginkan, serta menyoroti kemampuan manusia untuk menemukan dan memiliki makna dalam kondisi apapun. Pada penelitian yang dilakukan oleh Maryatun, Achir Yani dan Mustikasari menyatakan bahwa logoterapi dapat meningkatkan harga diri narapidana perempuan yang melakukan penyalahgunaan narkoba.

(Battyany, 2016) logoterapi memiliki tiga nilai dasar atau meaning triangle sebagai rute untuk menemukan makna, yaitu pertama: nilai kreatif, di mana konseli memberi kehidupan kembali dengan bekerja menggunakan kreativitas yang dimiliki, bakat unik sebagai 
pengalihan masalah dan memiliki hubungan sosial yang baik sehingga tidak terlibat dengan masalah yang sama lagi. Kedua, adalah pengalaman di mana konseli diminta untuk menerima pengalaman dalam hidup sebagai bagian dari belajar dan proses kehidupan sekalipun itu adalah pengalaman yang menyakitkan. Ketiga, nilai sikap yang dapat memberi makna adalah cara di mana konseli bertanggungjawab dan bersikap atas kesalahan yang pernah dibuat dengan membuatnya menjadi nilai baru yang ditunjukkan melalui sikap yang lebih positif dibanding sebelumnya. Berdasarkan penelitian yang dilakukan (Sutejo, 2017) bahwa logoterapi memberikan pengaruh terhadap kemampuan memaknai hidup pada pecandu narkoba di Rehabilitasi Sosial Permadi Putra Yogyakarta. Hal tersebut sangat mendukung peneliti untuk mengembangkan penelitian lebih lanjut terhadap logoterapi dan harga diri pada remaja pecandu narkoba.

Fenomena di atas menjadi dasar dalam penelitian ini. Penelitian ini bertujuan untuk melihat keefektivan logoterapi terhadap peningkatan harga diri remaja pecandu narkoba di Pondok Pesantren Bidaytussalikin. Harga diri rendah yang dimiliki oleh remaja pecandu narkoba harus ditangani dengan benar oleh konselor luar sekolah di rehabilitasi narkoba agar tidak terjadi kondisi relapse (kembali menunggunakan narkoba) setelah pecandu menjalani masa rehabilitasi. Sangat penting untuk dapat meningkatkan harga diri para remaja pecandu narkoba, agar remaja tersebut memiliki harapan dan percaya diri untuk menata masa depan kembali setelah keluar dari tempat rehabilitasi narkoba.

\section{METODE PENELITIAN}

Jenis penelitian dalam penelitian ini adalah quasi eksperiment dengan menggunakan non equivalent control group design. Dalam non equivalent control group design menurut (Campbell, 1963) terdapat kelompok eksperimen dan kelompok kontrol dan masing-masing akan diberikan pretest dan posttest dengan menggunakan skala harga diri yang 
terdiri dari 4 aspek menurut (Coopersmith, 1967) yaitu kekuasaan, keberartian, kebajikan dan kompetensi yang sudah di uji validitas dengan expert judgments dan reliabilitasnya dengan menggunakan rumus alpha crombach. Populasi dalam penelitian ini adalah 14 remaja pecandu narkoba yang akan diberikan pretest dengan menggunakan skala harga diri. Penentuan sampel menggunakan purposive sampling yang didasarkan pada ketentuan remaja pecandu narkoba tersebut memiliki harga diri pada kategori rendah. Berdasarkan kategori harga diri rendah diperoleh sampel sebanyak 10 remaja pecandu narkoba yang terbagi dalam dua kelompok yaitu kelompok kontrol dan eksperimen yang masing-masing kelompok terdiri dari 5 remaja pecandu narkoba yang memiliki harga diri rendah. Setelah terbentuk dalam 2 kelompok, kelompok eksperimen diberi perlakuan berupa logoterapi selama 9 kali pertemuan. Sedangkan kelompok kontrol diberikan perlakuan sebanyak 9 kali dan diberikan oleh staff rehabilitasi yaitu berupa pendekatan secara agama dengan terapi dzikir.

\section{HASIL DAN PEMBAHASAN}

Berdasarkan hasil penyebaran instrumen skala harga diri terhadap 5 sampel remaja pecandu narkoba diperoleh hasil pretest dan posttest yang dapat dilihat pada tabel di bawah ini:

Tabel 2. Hasil Pretest dan Posttest Harga Diri Remaja Pecandu Narkoba

\begin{tabular}{cccccc}
\hline NO & $\begin{array}{c}\text { Nama } \\
\text { (Inisial) }\end{array}$ & $\begin{array}{c}\text { Skor } \\
\text { Pretest }\end{array}$ & Kategori & $\begin{array}{c}\text { Skor } \\
\text { Posttest }\end{array}$ & Kategori \\
\hline 1 & DV & 45 & Rendah & 86 & Tinggi \\
2 & AN & 43 & Rendah & 82 & Tinggi \\
3 & CW & 39 & Rendah & 72 & Sedang \\
4 & PD & 40 & Rendah & 82 & Tinggi \\
5 & RA & 41 & Rendah & 71 & Sedang \\
\hline
\end{tabular}

Pada tabel 2 dapat dilihat bahwa terdapat peningkatan nilai dari nilai pretest. Kelima sampel remaja pecandu narkoba yang sebelum 
diberi perlakuan dengan logoterapi menunjukkan nilai harga dirinya rendah, sedangkan setelah diberikan perlakuan dengan logoterapi yang selanjutnya dilakukan posttest sangat terlihat adanya peningkatan harga diri yang signifikan.

Logoterapi dilakukan secara berkelompok dengan 5 remaja pecandu narkoba sebagai anggotanya. Tahapan dalam logoterapi ada 3 menurut (Soetan, 2014) yaitu tahap diagnosis, untuk membangun kepercayaan antara konselor dan konseli, tahap terapi konselor membantu konseli untuk berani menghadapi permasalahan dan menemukan cara dalam mengatasi masalah tersebut. Tahap selanjutnya adalah tindak lanjut konselor memantau kondisi konseli hingga kondisi stabil dan konseli melakukan perubahan perilakunya dalam menghadapi masalah. Secara keseluruhan perkembangan pretest dan posttest disajikan dalam gambar berikut ini:

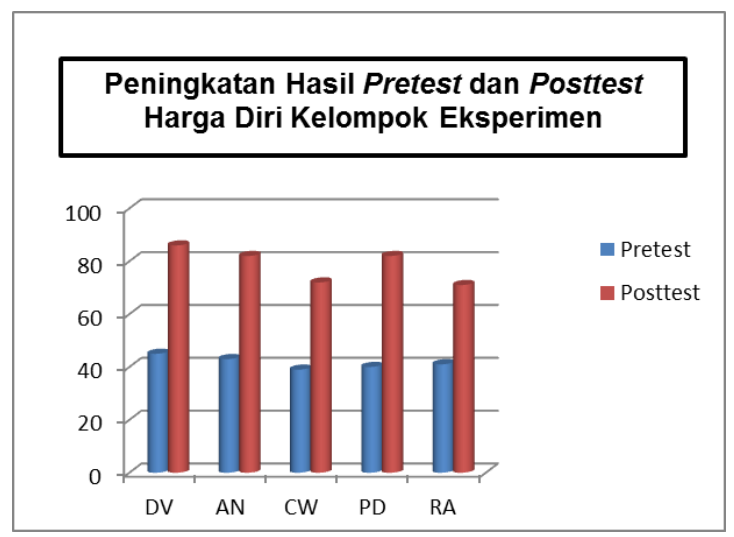

Gambar 1. Grafik Perkembangan Pretest dan Posttest Harga Diri Kelompok Eksperimen

Berdasarkan gambar di atas semua sampel mengalami peningkatan harga diri yang sangat signifikan setelah diberikan logoterapi. Adapun perubahan yang diamati adalah adanya peningkatan perilaku dalam mempengaruhi dan mengendalikan orang lain untuk mengikuti aturan dalam rehabilitasi, memiliki usaha untuk dapat diterima oleh orang lain, taat pada peraturan yang berlaku dan memiliki usaha untuk kembali memiliki prestasi.

Hal ini sejalan dengan penelitian dari (Jahanpour, et al, 2014) bahwa logoterapi efektif terhadap harga diri, 
kebahagian dan kecukupan sosial pada remaja putri di Tehranian. Masa remaja dan harga diri adalah masa perkembangan identitas yang sangat penting, harga diri bisa membawa remaja menuju perilaku positif ataupun perilaku negatif. Hal tersebut diperkuat oleh (Sowislo dan Orth, 2012) yang menjelaskan pentingnya harga diri bagi individu yaitu pertama, harga diri berfungsi sebagai sebuah monitor subjektif menilai diri sendiri sebagai anggota kelompok dan menilai hubungan sosial yang diinginkan oleh individu. Kedua, harga diri akan menuntun individu untuk hidup sesuai dengan aturan dan nilai-nilai budaya yang ada di masyarakat. Terdapat beberapa faktor yang dapat mempengaruhi harga diri remaja yaitu pengasuhan orangtua, keadaan sosial ekonomi keluarga, jenis kelamin, penenampilan fisik, penerimaan diri dan hubungan sosial dengan teman sebaya. Menurut (Freist J dan Freist G.J, 2010) harga diri yang tinggi akan membentuk individu memiliki rasa bangga dengan hasil kerjanya sendiri, individu menjadi mandiri dengan berani mengandalkan kemampuan yang dimiliki, dapat bertanggungjawab atas segala tindakan yang dilakukan, dapat memberikan pengaruh positif pada orang lain dan mampu menghadapi tantangan dengan antusias.

Untuk menumbuhkan hal tersebut maka dapat dilakukan dengan memberikan logoterapi. Hal ini sejalan dengan penelitian (Yildirim, 2018) bahwa logoterapi bertujuan untuk membantu individu menemukan makna dari kehidupannya bahkan dalam kondisi yang paling menyedihkan sekalipun. Logoterapi mendesak individu untuk menemukan makna hidup dan sikap optimis untuk melangkah ke masa depan yang individu inginkan.

\section{SIMPULAN}

Berdasarkan tujuan dan hasil pembahasan penelitian dapat ditarik kesimpulan bahwa logoterapi efektif terhadap harga diri pada remaja pecandu narkoba di Pondok Pesantren Bidayatussalikin Yogyakarta. Hasil dari pemberian perlakuan dengan logoterapi yaitu remaja pecandu narkoba mampu 
mempengaruhi dan mengajak orang lain untuk dapat mengatasi kecanduan terhadap narkoba, memiliki usaha untuk dapat beradaptasi dan diterima oleh orang lain dan lingkungan baru, berusaha untuk taat pada peraturan baik secara moral dan agama, serta berusaha untuk memiliki prestasi dan kembali optimis dalam menata masa depan. Hasil penelitian ini dapat digunakan oleh konselor luar sekolah sebagai salah satu terapi untuk membantu para pecandu narkoba dalam mengatasi harga diri rendah.

\section{DAFTAR PUSTAKA}

Batthyány, Alexander. (2016). Logotherapy and Existential Analysis: Proceedings of The Viktor Frankl Institute Vienna. Austria: Springer

Campbell, D.T., and Stanley, J.C. (1963). Experimental and Quasi-Exsperimental Design for Research. USA: Houghton Mifflin Company.

Coopersmith, Stanley. (1967). The Antecedents of Self Esteem. USA: W.H. Freeman and Company

Feist, J. and Feist, G.J. (2010). Teori Kepribadian (Terjemahan dari Handrianto). Jakarta: Salemba Humanika
Frankl, V.E. (1992). Man's Search for Meaning:An Introduction to Logotheraphy Four Edition. USA: Beacon Press

Graber, Anna V. (2004). Relevance and Application of Logotherapy to Enhance Resilience to Stress and Trauma. New York: Graduate Center for Pastoral Logotherapy

Guindon, Mary. H. (2010). SelfSteem Across The Lifespan Issues and Interventions. New York: Taylor and Francis Group

https://nasional.sindonews.com/read/ 1257498/15/40-penggunanarkoba-pelajar-mahasiswa1510710950

Jahanpour, Sareghin, Hosseini, and Tekiyee. (2014). The Study of Group Logo-therapy Effectiveness on Self-Esteem, Happiness and Social Sufficiency in Tehranian Girl Teenagers. Journal of Medical Sciences 2014 Vol. 7, Issue 3 No. 477489: Research Paper

Jahja, Yudrik. (2011). Psikologi Perkembangan. Jakarta: Kencana

Kimble, M.A., and Ellor, J.W. (2000). Logotherapy: An Overview. Reprinted from Viktor Frankl Contribution to Sprituality and Aging, a Monograph published simultaneously as The Journal of Religious Gerontology, Vol.11, No.3, pp.8-24

Maryatun, Sri., Achir Yani SH dan Mustikasari. (2014). Logoterapi 


\section{Meningkatkan Harga Diri Narapidana Perempuan Pengguna Narkoba. Jurnal Keperawatan Indonesia, Vol. 17, No.2, Juli 2014, hal 48-56 pISSN 1410-4490, eISSN 2354- 9203}

Melton, A and Schulenberg, S. (2008). On the Measurement of Meaning: $\quad$ Logotherapy Empirical Contributions to Humanistic Psychology. The Humanistic Psychology, Vol. 36, pp. 31-44

Murk, Chistopher. J. (2006). SelfEsteem Research, Theory and Practice Toward a Positive Psychology of Self-Esteem 3rd Edition. New York: Springer Publishing Company

Orth, U. Kali H, Trzesniewski. R.W. Robins. (2010). Self Esteem Development from Young Adulthood to Old Age: A Cohort-Sequential Longitudinal Study. Journal of Personality and Social Psychology, Vol. 98, No. 4, 645-658, DOI: $10.1037 / \mathrm{a} 0018769$

Plummer, Deborah. (2005). Helping Adolescents and Adult to Build Self-Esteem. London and Philadelphia: Jessica Kingsley Publishers

Pradana, Raden Bagus HA. (2015). Self-Esteem Hubungannya dengan Penyalahgunaan Narkotika dan Obat-obatan Berbahaya pada Siswa SMK Negeri 2 Batu Malang. Jurnal Konseling Indonesia 2015 Vol. 1, No. 1, hal. 23-28
Santrock, J. W. (2003). Adolesence: Perkembangan Remaja. Jakarta: Erlangga

Santrock, J. W. (2013). Adolescence: Fifteenth Edition. New York: McGraw-Hill

Schab, Lisa. M. (2013). The SelfEsteem Workbook for Teens: Activities to Help You Build Confidence and Achieve Your Goals. Oakland: Raincoast Books

Soetan, Margaret K. (2014). Logotherapy and Religion. Israel: OTSMOT Institute The Viktor Frankl Center for Logotheraphy in Israel

Sowislo, J. F., and Ulrich, Orth. (2012). Does Low Self-Esteem Predict Depression and Anxiety? A Meta-Analysis of Longitudinal Studies. American Psychological Association 2013, Vol. 139, No. 1, 213-240, DOI: $10.1037 / \mathrm{a} 0028931$

Sutejo. (2017). Pengaruh Logoterapi Kelompok terhadap Kemampuan Memaknai Hidup pada Residen Napza. Jurnal Ners dan Kebidanan Indonesia Vol. 5, No.1 tahun 2017, 27-32 ISSN 2354-7642

Undang-undang Nomor 35 Tahun 2009 tentang Narkotika

Yildrim, Dr. Ahmet. (2018). Logotherapy and Religion. Research Studies Anatolia Journal, Vol:1, Issue:2; pp: 3893932018 
52 | Jurnal Ilmiah Counsellia, Volume 9 No.1, Mei 2019| 39 - 52

Zamboanga, Byorn L., Seth J. Schwartz., Lorna Hernandez J and Kathryne Van Tyne. (2009). Acculturation and Substance Use Among Hispanic Early Adolescent: Investigating the Mediating Roles of Acculturative Stress and SelfEsteem. Springer: J Primary Prevent (2009) 30:315-333, DOI 10.1007/s10935-009-0182-z 